\title{
DNA Sequences Required for Regulated Expression of $\beta$-Globin Genes in Murine Erythroleukemia Cells
}

\author{
Stephanie Wright, * Amon Rosenthal, ${ }^{\dagger}$ \\ Richard Flavell,, and Frank Grosveld* \\ "Laboratory for Gene Structure and Expression \\ National Institute for Medical Research \\ The Ridgeway, Mill Hill \\ London NW7 1AA, England \\ tDepartment of Molecular Biology \\ The Hebrew University \\ Hadassah Medical School \\ Jerusalem, Israel \\ ‡Biogen Research Corporation \\ 14 Cambridge Center \\ Cambridge, Massachusetts 02142
}

\section{Summary}

We introduced into MEL cells rabbit $\beta$-globin gene deletion mutants and two sets of hybrid genes constructed from the inducible human $\beta$-globin gene and noninducible human $\gamma$-globin gene or the murine H-2K $\mathrm{Km}^{\mathrm{bm}}$ class I MHC gene. S1 nuclease analysis of gene transcripts before and after MEL differentiation showed that induction of the rabbit $\beta$-globin gene did not require more than 58 bp of DNA $5^{\prime}$ to the transcription initiation site. Hybrid genes were constructed with human $\beta$-globin DNA sequences from either $5^{\prime}$ or $3^{\prime}$ of the translation initiation site linked to the complementary parts of the $\gamma$ or H2K ${ }^{\mathrm{bm} 1}$ genes. Both types of constructs were inducible during MEL differentiation. The relative rates of transcription of the $5^{\prime} \gamma-3^{\prime} \beta$ and $5^{\prime} \mathrm{H} 2-3^{\prime} \beta$ hybrid genes show that induction of the hybrid gene transcripts results at least in part from transcriptional activation of the genes. We suggest that DNA sequences that regulate $\beta$-globin gene transcription during MEL differentiation are located both $5^{\prime}$ and $3^{\prime}$ to the translation initiation site.

\section{Introduction}

Murine erythroleukemia (MEL) cells are Friend virus trans formed enthroid cells that are arrested at the proerythroblast stage of differentiation (for review, see Marks and Rifkind, 1978). Cultured MEL cells may be induced to complete erythroid maturation by treatment with a variety of chemicals such as dimethylsulphoxide (DMSO) or hex amethylenebisacetamide (HMBA) (Friend et al., 1971; Reuben et al., 1976; Marks and Rifkind, 1978). This chemically triggered maturation closely resembles normal erythroid differentiation and results in an accumulation of mouse adult globin mRNA in the differentiated cell (Ross et al., 1972; Nudel et al., 1977; Orkin and Swerdlow, 1977). The accumulation of globin transcripts results from both transcriptional activation of the mouse globin genes and an increase in the relative stability of globin mRNA. One approach in studying the DNA sequences that regulate globin gene activation during erythroid differentiation is to analyze the expression of cloned globin genes introduced into MEL cells (Spandidos and Paul, 1982; Wright et al., 1983; Chao et al., 1983).

We have previously introduced genes from the human $\beta$-like globin gene cluster containing the embryonic $(\epsilon)$, fetal $(\gamma)$, and adult $(\beta)$ genes into MEL cells (Wright et al., 1983). Transcription of the foreign adult $\beta$-globin gene was induced following MEL differentiation, whereas expression of the fetal $(\gamma)$ and embryonic $(\epsilon)$ genes was not regulated. This specific induction of the human adult $\beta$-globin gene therefore mimicked globin gene activation during adult type erythropoiesis and showed that the information required for regulation of the human $\beta$-globin gene resided within the introduced DNA sequences.

In the experiments described here, we have localized the DNA sequences that regulate the activation of an introduced $\beta$-globin gene in MEL cells. The results suggest that the DNA sequences required for regulation of $\beta$-globin gene expression during erythroid differentiation are located both $5^{\prime}$ and $3^{\prime}$ to the translation initiation codon.

\section{Results}

\section{Regulated Expression of Rabbit $\beta$-Globin Gene} Deletion Mutants in MEL Cells

in order to determine whether specific DNA sequences within the $5^{\prime}$ flanking region of the $\beta$-globin gene regulate their activation during erythroid differentiation, rabbit $\beta$ globin gene deletion mutants as shown in Figure 1 were introduced into MEL cells. We analyzed the expression of a rabbit $\beta$-globin gene with 425 bp of DNA $5^{\prime}$ to the transcription initiation site and three mutants containing truncated $5^{\prime}$ ends. The first of these had 100 bp of DNA $5^{\prime}$ to the transcription initiation site and thus contained all the DNA sequences required for transcription (Grosveld et al., 1982a, 1982b; Dierks et al., 1981). This -100 mutant therefore enabled us to determine whether the regulatory DNA sequences required for induction reside within or outside the promoter boundary. The other mutants had deletions within the conserved sequence boxes required for transcription per se; the $\nabla-76-93$ mutant thus lacked the conserved -90 region, and the -58 mutant, which had only 58 bp $5^{\prime}$ to the transcription initiation site, lacked both the conserved -90 region and CAAT box. The rabbit $\beta$-globin gene mutants had been constructed in vectors which contained SV40 DNA sequences (Grosveld et al., $1982 a, 1982 b$ ). These sequences were removed prior to transformation by digestion with Hind III. The resultant rabbit $\beta$-globin fragments were transfected into tk- MEL cells with a Pvu I linearized human $\beta$-globin cosmid, $\beta$-pRT. This cosmid contains the $4.7 \mathrm{~kb}$ human $\beta$-globin gene Bgl \| fragment cloned into the Bam HI site of the HSV-tk cosmid pRT. The expression of the cotransferred human $\beta$-globin gene served as a control for induction of the introduced DNA since previous experiments have shown this human $\beta$-gene to be inducible in $80 \%$ of MEL transformants (Wright et al., 1983). Stable $\mathrm{tk}^{+}$transformants were obtained at frequencies of 5-20 clones per micro- 


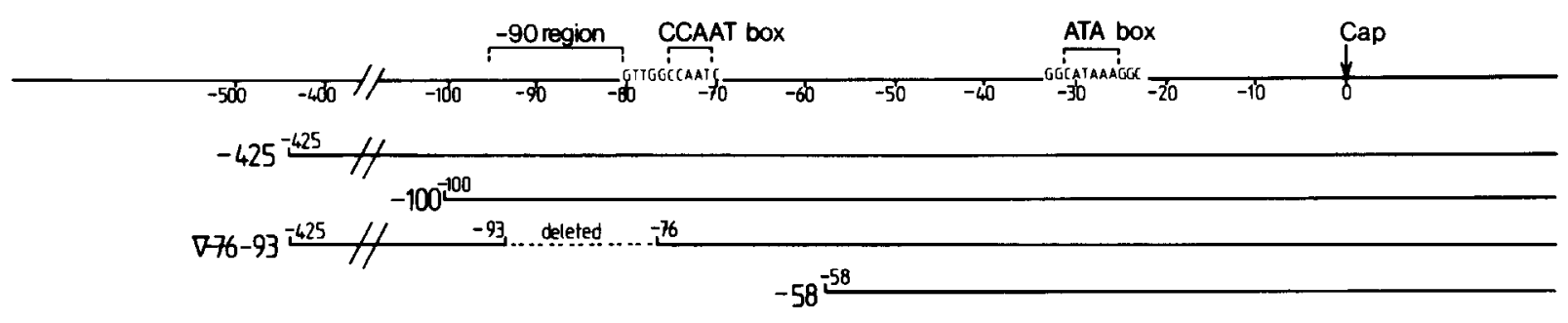

Figure 1. Structure of Rabbit $\beta$-Globin Gene Deletion Mutants

Deletions within the $5^{\prime}$ flanking region of the rabbit $\beta$-globin gene were as shown. The construction of these mutants was described in Grosveld et al., 1982 .

gram $\beta$-pRT per $10^{6}$ cells. Seven to ten transformants containing each of the mutants were induced to differentiate by culturing for three days in the presence of $3 \mathrm{mM}$ HMBA, and levels of mouse $\beta$-major-, human $\beta$-, and rabbit $\beta$-globin transcripts were measured by $S 1$ nuclease analysis using probes that detected the $5^{\prime}$ or $3^{\prime}$ ends of these mRNAs. The MEL cell transformants that showed inducibility for the human and mouse $\beta$-globin genes were subsequently analyzed for expression of the foreign rabbit $\beta$-globin gene by S1 nuclease mapping (Berk and Sharp, 1977; Weaver and Weissmann, 1979) (Figure 2). Hybridization of correctly terminated rabbit $\beta$-globin gene transcripts to the 900 nucleotide $3^{\prime}$ labeled Eco RI probe yielded a 172 nucleotide fragment which was protected from S1 nuclease digestion. Similarly, hybridization of correctly initiated rabbit $\beta$-globin gene transcripts to the 221 nucleotide 5 ' labeled Bst NI probe yielded a 139 nucleotide $\mathrm{S} 1$ nuclease protected fragment. Figure 2 also shows the induction of endogenous mouse $\beta$-globin mRNA in the same MEL transformants as measured by $S 1$ nuclease analysis of the $3^{\prime}$ end of the mRNA. All S1 nuclease analyses were carried out using an excess of DNA in the hybridization reaction, and the intensity of the $S 1$ nuclease protected fragments was, therefore, proportional to the amount of globin mRNA present. Six out of six MEL transformants containing the -425 rabbit $\beta$-globin gene showed a 10 - to more than 40 -fold increase in rabbit $\beta$ globin mRNA levels upon differentiation. Induced mRNA levels corresponded to $500-3000$ copies rabbit $\beta$-globin mRNA per cell. A similar inducibility was observed for the -100 rabbit $\beta$-globin gene mutant (Figure 2), thus indicating that DNA sequences $5^{\prime}$ to the promoter are not essential for activation of the gene. Four out of seven transformants containing the $\nabla-76-93$ mutant and three out of six transformants containing the $\mathbf{- 5 8}$ mutant showed inducibility of correctly initiated rabbit $\beta$-globin gene transcripts. The absolute levels of rabbit $\beta$-globin mRNA varied extensively between different transformants containing the $\nabla-76-93$ and -58 mutants (Figure 2, the first and second examples of both the $\nabla \cdot 76-93$ and the -58 mutants). Consequently, a large number of transformants would have to be analyzed to obtain an accurate representative mRNA level for each mutant. Nevertheless, the average level from the small numbers of transformants analyzed is lower in the $\nabla-76-93$ and -58 clones than in the -425 and -100 rabbit $\beta$-globin transformants. This is presumably due to the effect of these promoter deletions on the efficiency of transcription per se (Dierks et al., 1981; Grosveld et al., 1982a, 1982b). Thus removal of DNA sequences that are required for transcription per se resulted in a reduction in the efficiency of transcription, but did not affect gene activation. Deletion mutations which removed part of the conserved ATA box resulted in so great a reduction in transcription of the gene that evaluation of their inducibility in MEL cells was not feasible (not shown). These data therefore indicate that not more than 58 bp of DNA $5^{\prime}$ to the transcription initiation site is required for induction of the transfected rabbit $\beta$-globin gene in MEL cells.

\section{Regulated Expression in MEL Cells of Gene Hybrids Containing a 5' Human $\beta$-Globin Region}

Expression of the rabbit $\beta$-globin gene deletion mutants in MEL transformants indicated that the DNA sequences required for induction reside either within the $3^{\prime}$ region of the promoter or downstream of the transcription initiation site. In order to distinguish between these possibilities, we constructed hybrid genes between the inducible human $\beta$-globin gene and either the noninducible human $\gamma$-globin gene or the noninducible mouse $\mathrm{H}-2 \mathrm{~K}^{\mathrm{bm} 1}$ gene (Weiss et al., 1983).

We have previously shown that the human $\gamma$-globin gene is not induced in MEL cells when it is introduced as part of a large cosmid recombinant. This was confirmed by analyzing in MEL cells the expression of the human $\gamma$ globin clone $\gamma$-pRT, which contained the A $\gamma$-globin $3 \mathrm{~kb}$ Hind III fragment inserted in the tk vector pRT. Only one out of $12 \gamma$-pRT transformants showed inducibility of human $\gamma$-globin mRNA (Figure 3a).

In order to determine whether the mouse $\mathrm{H}-2 \mathrm{~K}^{\mathrm{bm} 1}$ gene is inducible, pTME10, which contains the $\mathrm{H}-2 \mathrm{~K}^{\mathrm{bm} 1}$ gene on a $10 \mathrm{~kb}$ Eco RI fragment, was introduced into MEL cells by cotransfection with the HSV-tk vector pRT. Levels of $H$ $2 \mathrm{~K}^{\mathrm{bm} 1}$ transcript in $12 \mathrm{MEL}$ transformants were measured by $S 1$ nuclease analysis using a 600 nucleotide probe that spanned the junction between the third exon and third intron of the $\mathrm{H} 2-\mathrm{K}^{\mathrm{b}}$ gene. Because the $\mathrm{H} 2-\mathrm{K}^{\mathrm{b}}$ and $\mathrm{H} 2-\mathrm{K}^{\mathrm{bm} 1}$ genes differ in the third exon (Weiss et al., 1983), hybridization of this probe to $\mathrm{H}-2 \mathrm{~K}^{\mathrm{bm} 1}$ transcripts yields a 140 nucleotide fragment that is protected from digestion by $\mathrm{S} 1$ nuclease (Rosenthal et al., submitted). None of these 12 MEL transformants showed inducibility of $\mathrm{H}-2 \mathrm{~K}^{\mathrm{bm} 1}$ transcripts (Figure 3b).

In order to determine whether human $\beta$-globin DNA 

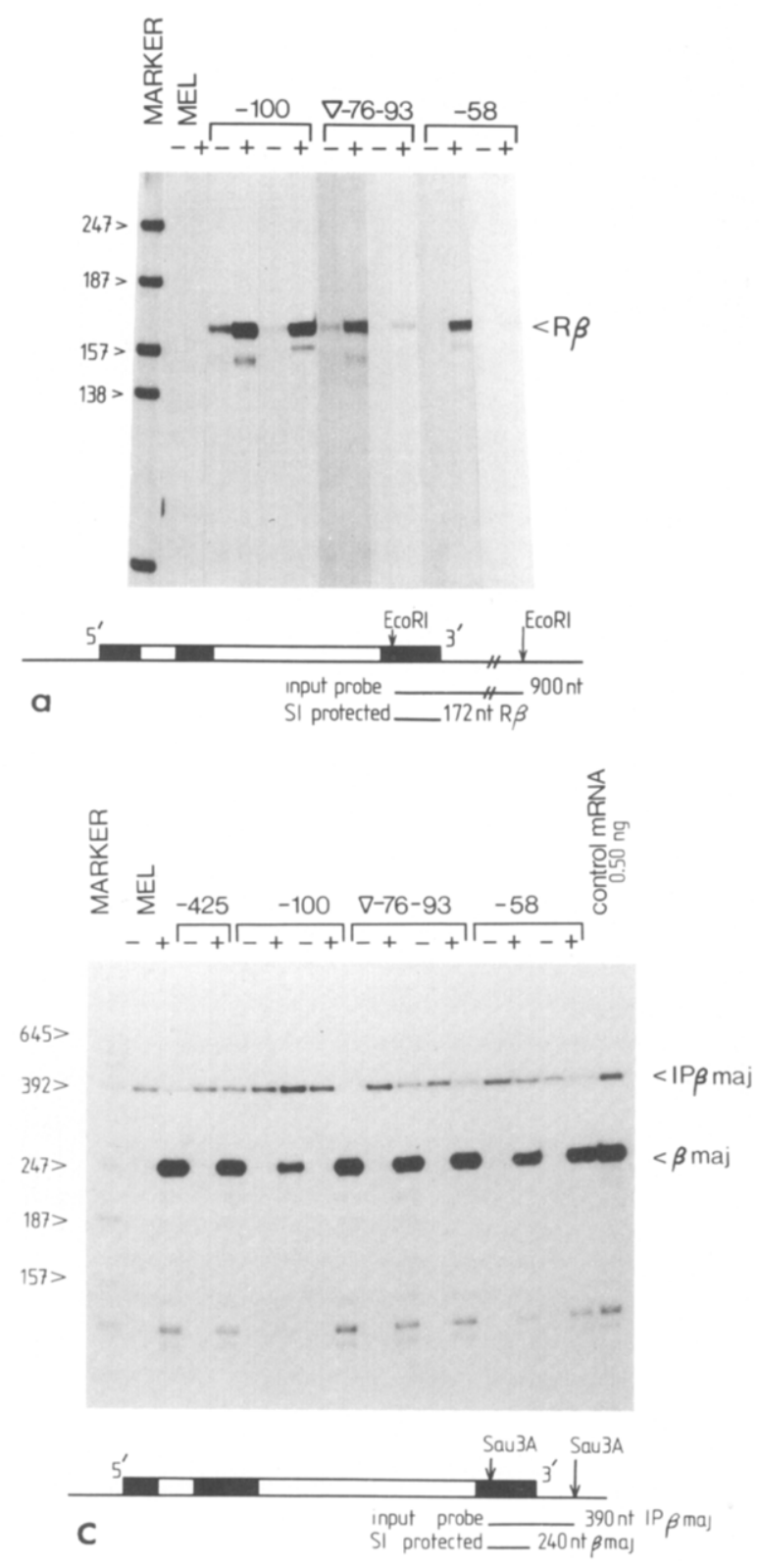

sequences $5^{\prime}$ to the translation initiation site can confer inducibility upon a noninducible gene, they were adjoined to the complementary $3^{\prime}$ region of the noninducible human $\gamma$-globin and mouse $\mathrm{MHCH}-2 \mathrm{~K}^{\mathrm{bm} 1}$ genes. The construction of these hybrid genes is shown in Figure 4, using the Nco I site at the translation initiation site of the $\beta$ - and $\gamma$-genes.

The hybrid gene containing the $5^{\prime}$ region of the human $\beta$-globin gene joined to the $3^{\prime}$ region of the $\gamma$-globin gene $\left(5^{\prime} \beta-3^{\prime} \gamma\right)$ was introduced into tk MEL cells. Ten transformants were induced into differentiation and transcripts from the introduced hybrid gene were quantitated by $\mathrm{S} 1$ nuclease analysis using a probe that detected the $3^{\prime}$ end of human $\gamma$-globin mRNA. Five transformants showed a 5 to 50 -fold induction of the $5^{\prime} \beta-3^{\prime} \gamma$ hybrid transcript upon differentiation (Figure $5 \mathrm{a}$ ).

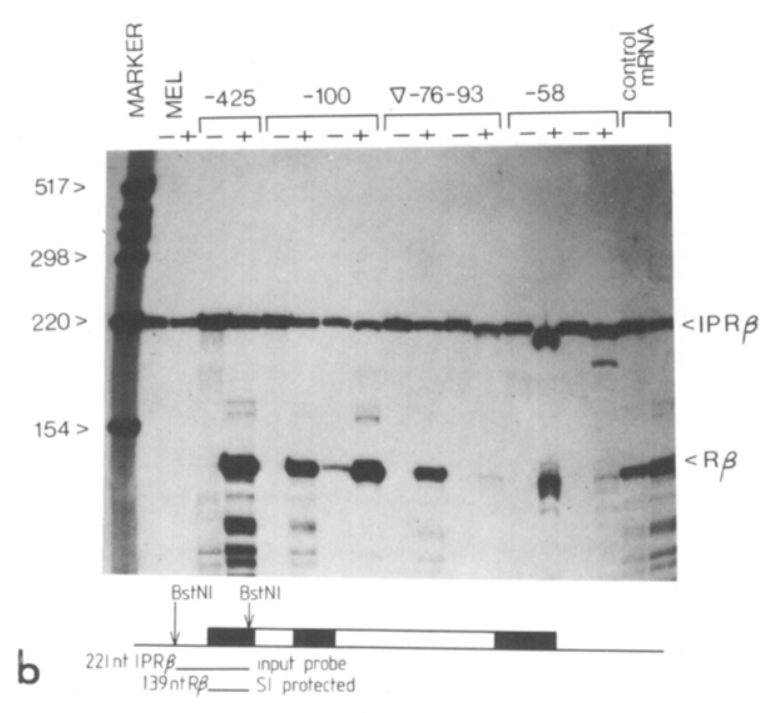

Figure 2. S1 Nuclease Analysis of Rabbit $\beta$-Globin Transcripts in MEL Transformants

(a) Individual MEL transformants containing the rabbit $\beta$-globin gene deletion mutants indicated were grown for three days in the presence $(+)$ or absence $(-)$ of $3 \mathrm{mM}$ HMBA. Ten microgram samples of total cellular RNA were hybridized at $52^{\circ} \mathrm{C}$ to the end-labeled $3^{\prime}$ rabbit $\beta$-globin gene probe illustrated. Control RNA was obtained from rabbit bone marrow. (b) $\mathrm{S} 1$ nuclease analysis of the $5^{\prime}$ end of rabbit $\beta$-globin transcripts in MEL transformants. RNA from MEL transtormants corresponding to those described in (a) was analyzed using the rabbit $\beta$-globin gene $5^{\prime}$ probe illustrated (IPR $\beta$ ). Hybridizations contained $100 \mu \mathrm{g}$ RNA and were carried out at $37^{\circ} \mathrm{C}$ using a strand-separated probe. (C) $\mathrm{S} 1$ nuclease analysis of mouse $\beta$-major globin transcripts in MEL transformants. Levels of mouse $\beta$-major globin mRNA in MEL transformants corresponding to those shown in (a) were measured by $S 1$ nuclease mapping using the $3^{\prime}$ mouse $\beta$-major globin gene probe illustrated (IP $\beta$ maj.). Hytridizations were at $52^{\circ} \mathrm{C}$ and contained $2 \mu \mathrm{g}$ total cellular RNA. Control RNA was obtained from mouse reticulocytes.

In another set of transformations, the $5^{\prime} \beta-3^{\prime} \mathrm{H} 2$ hybrid gene was introduced into $\mathrm{t}^{-}$MEL cells by cotransfection with the HSV-tk vector $\mathrm{pRT}$. Two out of three transformants containing this hybrid gene showed an induction of hybrid gene transcript as measured by $\mathrm{S} 1$ nuclease analysis using the $\mathrm{H}-2 \mathrm{~K}^{\mathrm{b}}$ gene exon-intron probe (Figure $5 \mathrm{~b}$ ).

\section{Regulated Expression in MEL Cells of Gene Hybrids Containing the Human $\beta$-Globin Gene 3' Region}

We have also analyzed the expression in MEL cells of hybrid genes in which only DNA sequences $3^{\prime}$ to the translation initiation codon were derived from the human $\beta$-globin gene. The construction of these hybrid genes $\left(5^{\prime}\right.$. $\mathrm{H}-2 \mathrm{~K}^{\mathrm{bm}-1}-3^{\prime} \beta$ and $5^{\prime} \gamma-3^{\prime} \beta$ ) is shown in Figure 6. 

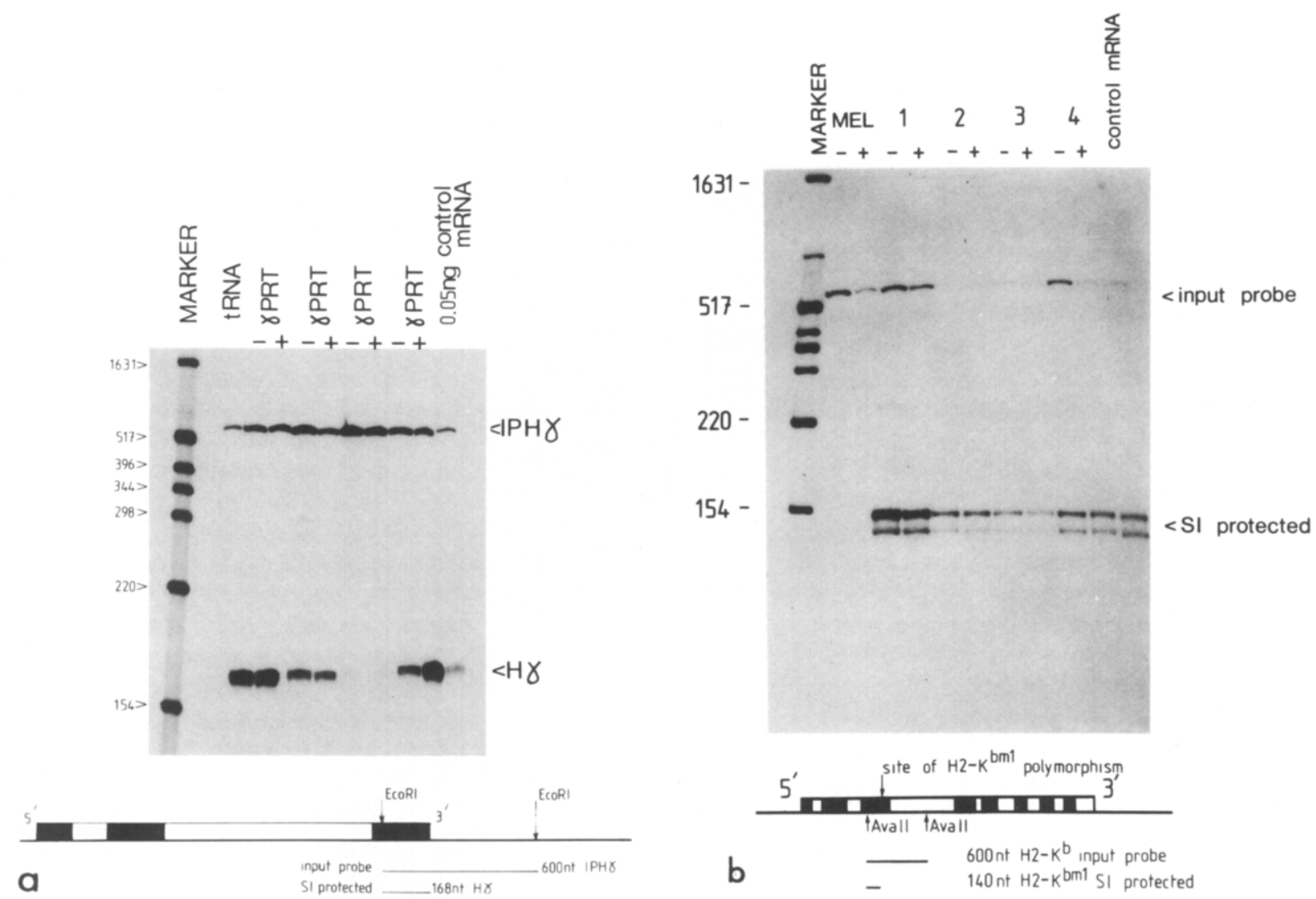

Figure 3. S1 Nuclease Analysis of Human $\gamma$-Globin Gene Transcripts in MEL Transformants Containing $\gamma$-pRT

(a) Thitty microgram samples of RNA from noninduced $(-)$ and induced (+) MEL transformants containing $\gamma$-DRT were analyzed by $S 1$ nuclease mapping using the $3^{\prime} \gamma$-globin gene probe illustrated $(\mathbb{P H} \gamma \gamma)$. Hybridization was at $52^{\circ} \mathrm{C}$. Control RNA was obtained from a patient with $\beta^{\circ} / \delta \beta^{\circ}$ thalassaemia. (b) $\mathrm{S} 1$ nuclease analysis of $\mathrm{H}-2 \mathrm{~K}^{\mathrm{bm}}$ transcripts in MEL transformants containing the $\mathrm{H}-2 \mathrm{~K}^{\mathrm{bm} / 1}$ cosmid PTME10. PTME10 contained the $10 \mathrm{~kb} \mathrm{H}-2 \mathrm{~K}^{\mathrm{bm}}$ gene Eco RI fragment cloned in the Eco Rl site of the pTM cosmid vector. Ten microgram samples of total cellular RNA from noninduced $(-)$ and induced $(+)$ MEL transformants containing pTME10 were analyzed by $\mathrm{S} 1$ nuclease mapping using the $\mathrm{H}-2 \mathrm{~K}^{\mathrm{b}}$ gene exon-intron probe illustrated. The DNA sequence of the $\mathrm{H}$ $2 \mathrm{~K}^{\mathrm{b}}$ and $\mathrm{H}-2 \mathrm{~K}^{\mathrm{bm} 1}$ genes differ in the third exon at the position indicated. Hybridization of $\mathrm{H}-2 \mathrm{~K}^{\mathrm{bm} 1}$ transcripts to the $\mathrm{H}-2 \mathrm{~K}^{\mathrm{b}}$ gene probe thus yields a 140 nucleotide fragment which is protected from $S 1$ nuclease digestion. Hybridization was at $60^{\circ} \mathrm{C}$ and $\mathrm{S} 1$ digestion was for $1 \mathrm{hr}$ at $20^{\circ} \mathrm{C}$ followed by $1 \mathrm{hr}$ at $40^{\circ} \mathrm{C}$. Control RNA was obtained from the liver of an $\mathrm{H}-2 \mathrm{~K}^{\mathrm{bm}}$ mouse.

The $5^{\prime} \gamma-3^{\prime} \beta$ and $5^{\prime} \mathrm{H} 2-3^{\prime} \beta$ hybrid genes were introduced into tk ${ }^{-}$MEL cells by cotransfection with $\mathrm{pRT}$. Upon differentiation, four out of eight transformants containing the $5^{\prime} \gamma-3^{\prime} \beta$ gene showed a 5 - to more than 100 -fold induction of hybrid gene transcript as measured by $\mathrm{S1}$ nuclease analysis using a probe which detected the $3^{\prime}$ end of human $\beta$-globin mRNA (Figure $7 \mathrm{a}$ ). Four out of five transformants containing the $5^{\prime} \mathrm{H}-2 \mathrm{~K}^{\mathrm{bm} 1}-3^{\prime} \beta$ hybrid gene showed a similar induction of hybrid gene transcript (Figure 7b).

The accumulation of mouse globin mRNA in differentiating MEL cells results from both an increase in the rate of globin gene transcription and an increase in the relative stability of globin mRNA. Similarly, the induction of introduced hybrid genes containing human $\beta$-globin structural gene sequences $\left(5^{\prime} \gamma-3^{\prime} \beta\right.$ and $\left.5^{\prime} \mathrm{H}-2 K^{\mathrm{bm} 1}-3^{\prime} \beta\right)$ may be due to either an increase in the relative stability of the hybrid gene transcript or to an increase in the rate of transcription of these genes. In order to distinguish between these two possibilities, we measured the relative rate of transcription of these hybrid genes before and after differentiation using a nuclear run-off transcription assay (Groudine et al., 1981; Hofer et al., 1982).

Nuclei were isolated before and after differentiation from two MEL transformants containing the $5^{\prime} \mathrm{H} 2-3^{\prime} \beta$ and $5^{\prime} \gamma$ $3^{\prime} \beta$ hybrid genes. In these two transformants, the induction and expression level of the foreign hybrid gene was approximately equal to that of the endogenous mouse $\beta$ major globin gene, as measured by $\mathrm{S} 1$ nuclease. Isolated nuclei were incubated in a nuclear transcription reaction containing ${ }^{32}$ P.UTP, which was therefore incorporated into newly synthesized RNA. RNA was extracted and hybridized to specific globin gene DNA probes that were immobilized as dots on nitrocellulose filters. The probes were isolated from the second IVS of the mouse and human $\beta$ globin genes for two reasons; first, maximal sequence divergence between the mouse and human genes is located in this region. Second, these probes hybridize only to precursor mRNA. DNA probes were present in vast excess over the specific globin transcripts and conse- 


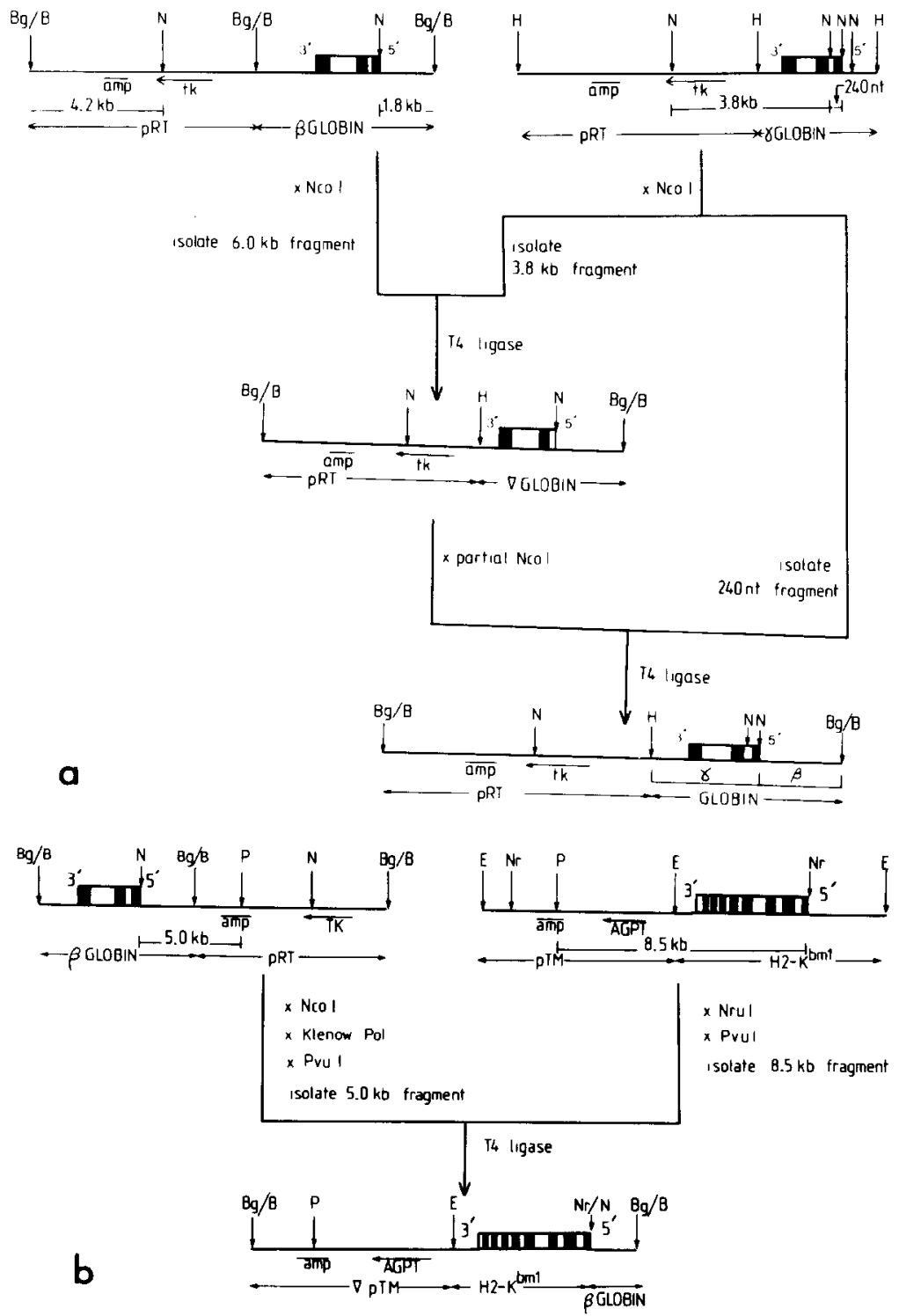

Figure 4. Construction of $5^{\prime} \beta-3^{\prime} \gamma$ and $5^{\prime} \beta-3^{\prime} \mathrm{H}$. 2K ${ }^{\mathrm{bml}}$ Hybrid Genes

Hybrid genes were constructed from the globin and $\mathrm{H}-2 \mathrm{~K}^{\mathrm{bm} 1}$ gene subclones as described in the diagrams.

$\mathrm{N}, \mathrm{P}, \mathrm{E}, \mathrm{Nr}$, and $\mathrm{Bg} / \mathrm{B}$ refer to $\mathrm{Nco} \mathrm{I}, \mathrm{Pvu} \mathrm{I}, \mathrm{Eco}$ Rl, Nru I, and joined Bgl II-Bam Hll sites, respectively.

quently, the amount of hybridizing labeled nuclear RNA was proportional to the rate of transcription of the globin gene. All hybridizations contained RNA isolated from an equal number of nuclei, so that differences in the absolute rate of gene transcription could be measured (see Experimental Procedures).

Hybridization of labeled nuclear transcripts from nontransformed MEL nuclei before and after differentiation is shown in Figure 8. Differentiation of the MEL cells resulted in an increase in hybridization to the mouse IVS2 probe, indicating an increase in the rate of transcription of the mouse $\beta$-major globin gene. In contrast, no increase in hybridization to the human IVS2 probe was observed, showing that the labeled mouse globin mRNA did not cross-hybridize with the human $\beta$-globin gene probe. Labeled nuclear transcripts from MEL transformants containing the $5^{\prime} \gamma-3^{\prime} \beta$ and $5^{\prime} \mathrm{H} 2-K^{\mathrm{bm} 1}-3^{\prime} \beta$ hybrid genes showed an increase in hybridization to both mouse and human probes upon differentiation, indicating an increase in the rate of transcription of both the endogenous mouse globin and introduced hybrid globin genes. Thus the increase in the level of hybrid $5^{\prime} \gamma-3^{\prime} \beta$ and $5^{\prime} H 2-K^{b m 1}-3^{\prime} \beta$ gene transcripts following MEL differentiation resulted at least in part from an increase in the rate of transcription of these genes.

\section{Discussion}

By introducing into MEL cells a series of rabbit $\beta$-globin gene deletion mutants, we have shown that no more than 58 bp of DNA $5^{\prime}$ to the transcription initiation site are required for induction of the $\beta$-globin gene during erythroid differentiation. We also analyzed the expression in MEL cells of hybrid genes in which DNA sequences $5^{\prime}$ to the translation initiation codon were derived from the human $\beta$-globin gene $\left(5^{\prime} \beta-3^{\prime} \gamma\right.$ and $\left.5^{\prime} \beta-3^{\prime} \mathrm{H}-2 K^{b m 1}\right)$. Expression of these hybrid genes was induced during differentiation, 

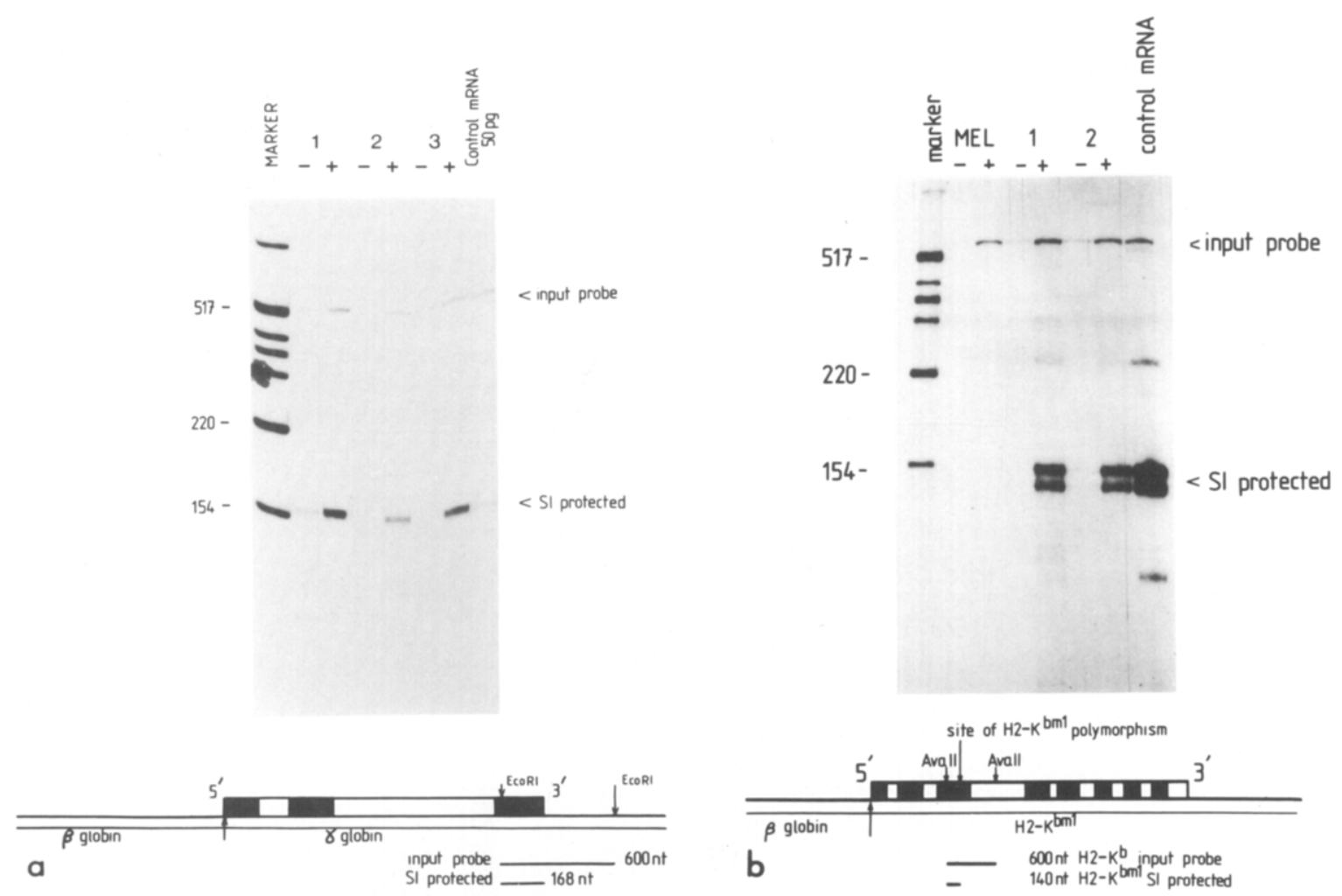

Figure 5. (a) S1 nuclease mapping of $5^{\prime} \beta-3^{\prime} \gamma$ hybrid gene transcripts in MEL transformants. Ten microgram samples of total celluar RNA from noninduced $(-)$ and induced $(+)$ MEL transformants were analyzed by $S 1$ nuclease mapping using the $3^{\prime}$ human $\gamma$-globin gene probe illustrated. Hybridization was at $52^{\circ} \mathrm{C}$. Control RNA was from a patient with $\beta^{0} / \delta \beta^{0}$ thalassaemia. (b) S1 nuclease mapping of $5^{\prime} \beta-3^{\prime} \mathrm{H}-2 \mathrm{~K}^{\mathrm{bm}}$ transcripts in MEL transformants. Eighty microgram samples of RNA from noninduced $(-)$ and induced $(+)$ MEL transformants were analyzed by $S 1$ nuclease analysis using the $H-2 K^{\circ}$ gene probe as described in Figure 4.

showing that the human $\beta$-globin $5^{\prime}$ flanking DNA sequences can confer inducibility on the noninducible human $\gamma$-globin and mouse $\mathrm{H}-2 \mathrm{~K}^{\mathrm{bm} 1}$ genes. In addition, we analyzed the expression of hybrid genes in which only DNA sequences $3^{\prime}$ to the translation initiation codon were derived from the human $\beta$-globin gene $\left(5^{\prime} \gamma-3^{\prime} \beta\right.$ and $5^{\prime} \mathrm{H}$ $2 \mathrm{~K}^{\mathrm{bm}}-3^{\prime} \beta$ ). Interestingly, we observed an increased level of transcripts from these hybrid genes upon MEL differentiation. Measurement of the relative rate of transcription of these hybrid genes by nuclear transcription run-off analysis showed that these increased levels of hybrid transcript resulted at least in part from transcriptional activation of the genes upon differentiation. We therefore suggest that DNA sequences required for activation of the $\beta$-globin gene during erythropoiesis are found both $5^{\prime}$ and $3^{\prime}$ to the translation initiation codon.

Several cloned genes have been shown to be expressed in a regulated manner after introduction into an appropriate eucaryotic cell line e. g., the growth hormone (Robins et al., 1982) and $\alpha$-2 globulin (Kurtz, 1981) synthesis are inducible by glucocorticoids after the introduction of these genes into $L$ cells that contain receptors for this hormone, and the Drosophila heat shock genes are inducible by high temperature after introduction into a variety of cell types (Pelham and Bienz, 1982). Approaches to localize the regulatory DNA sequences that confer inducibility on the foreign gene have involved studying the expression of in vitro constructed deletion mutants and hybrid genes. In all cases studied thus far, the foreign gene is expressed in a regulated manner after transfer into cells as a short DNA fragment containing only several hundred base pairs of DNA 5' to the gene. In some systems, most notably in the induction of the interferon (Ragg and Weissmann, 1983; Weidle and Weissmann, 1983; Zinn et al., 1983) and heat shock genes (Pelham and Bienz, 1982), a distinct region within the $5^{\prime}$ flanking region of the gene has been shown to confer inducibility on an otherwise noninducible gene. In other cases, however, the presence of regulatory DNA sequences $3^{\prime}$ to the cap site of the gene has not always been rigorously investigated. There are several well-defined examples of gene transcription being influenced by DNA sequences located $3^{\prime}$ to the cap site. These include the internal promoter region of the Xenopus 5S RNA gene (Bogenhagen et al., 1980), which is required for transcription per se, and the tissue-specific enhancer of the immunoglobulin gene (Queen and Baltimore, 1983; Banerji et al., 1983), which is located in an intron upstream of the constant region gene and which probably serves to activate the variable region promoter of the functionally rearranged immunoglobulin gene in the lymphocyte. In addition, the expression of a foreign gene in a eucaryotic cell may be increased by a viral enhancer sequence when the 


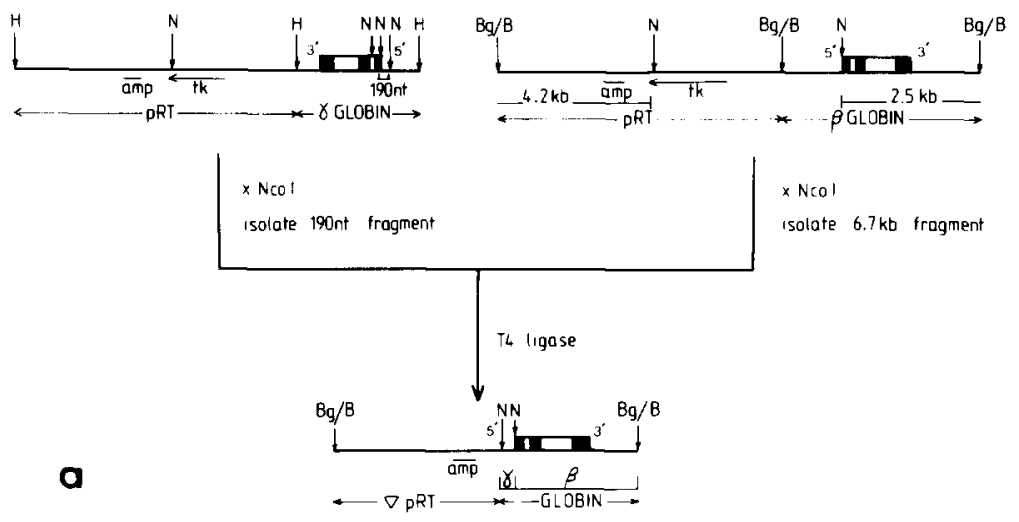

Figure 6. Construction of $5^{\prime} \gamma \cdot 3^{\prime} \beta$ and $5^{\prime} \mathrm{H}-2 \mathrm{~K}^{\mathrm{om}}$. 3' $\beta$ Hybrid Genes

Hybrid genes were constructed from globin and $\mathrm{H}-2 \mathrm{~K}^{\mathrm{bm}}$ gene subclones as described in the dia. gram. N. P, E. K, and Bgl/B refer to Nco I, Puu I, Eco Rl, Kpn I, and joined Bgl I-Bam HI sites, respectively.
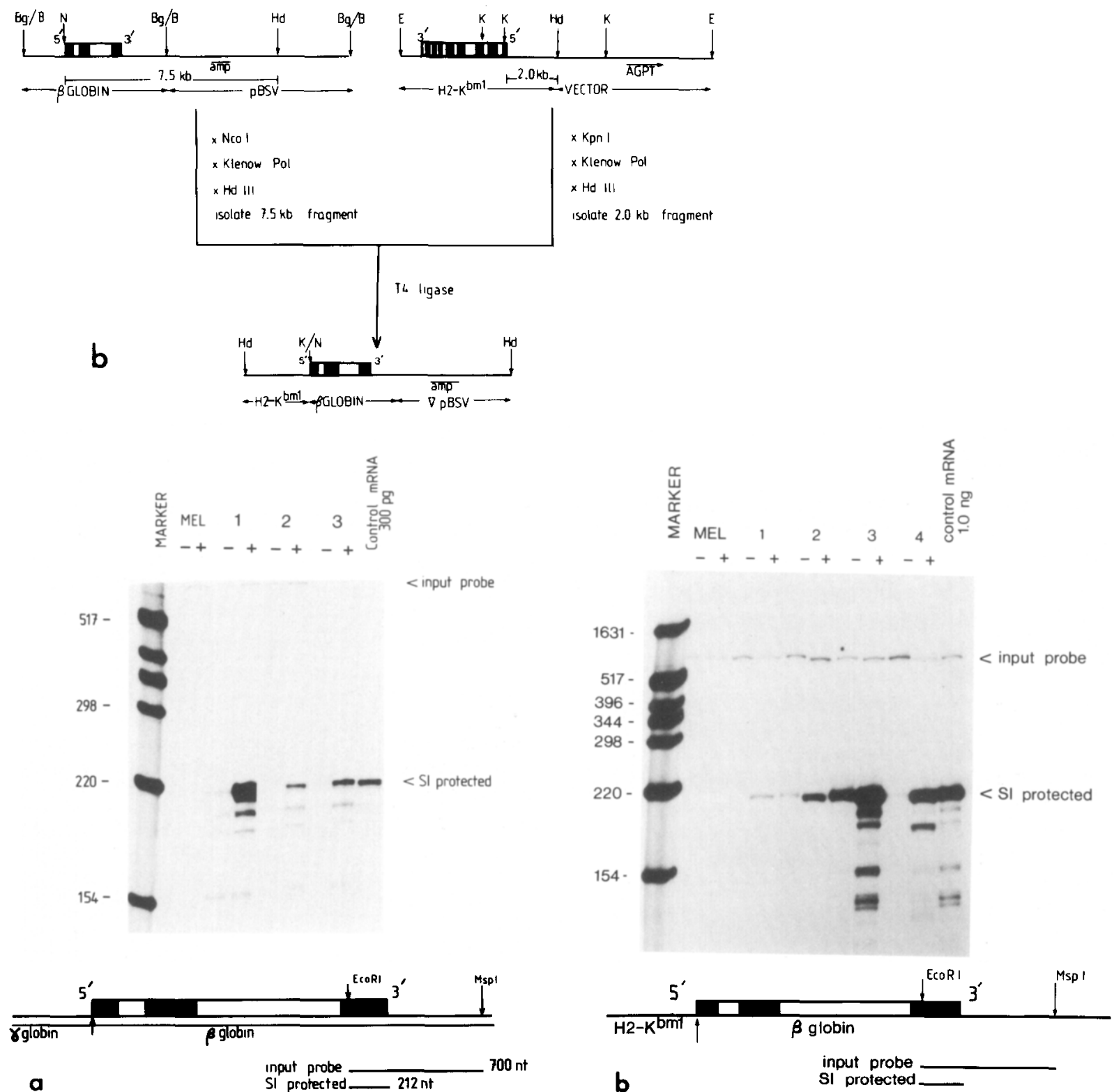

Figure 7. (a) $S 1$ nuclease analysis of $5^{\prime} \gamma-3^{\prime} \beta$ transcripts in MEL transformants. Ten microgram samples of total cellular RNA from induced and noninduced $(-)$ MEL transformants were analyzed using the $3^{\prime}$ human $\beta$-globin probe illustrated. Hybridization was at $52^{\circ} \mathrm{C}$. Control RNA was obtained from a patien with sickle cell anemia. (b) S1 nuclease analysis of $5^{\prime} \mathrm{H}^{2} \mathrm{~K}^{\mathrm{om}}{ }^{-1} 3^{\prime} \boldsymbol{\beta}$ transcripts in MEL transformants. Ten microgram samples of total cellular RNA from MEL transtormants containing the $5^{\prime} \mathrm{H} 2 \mathrm{~K}^{\mathrm{bm} 1}-3^{\prime} \beta$ hybrid gene were analyzed as in (a). 

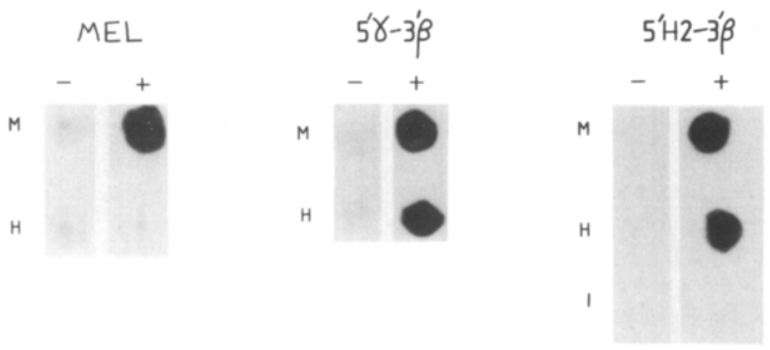

Figure 8. Dot Hybridization of Labeled Nuclear Transcripts from MEL Transformants

Nuclei were isolated from induced $(+)$ and noninduced $(-)$ individual MEL $5^{\prime} \gamma-3^{\prime} \beta$ (Figure $7 \mathrm{a}$, clone 1) and $5^{\prime} \mathrm{H} 2-3^{\prime} \beta$ (Figure $7 \mathrm{~b}$, clone 4) transformants. RNA synthesized in these isolated nuclei was labeled for 20 min with ${ }^{32} \mathrm{P}$-UTP as described in Experimental Procedures. Nuclear transcripts were hybridized to human $\beta$-globin $(\mathrm{H})$, mouse $\beta$-major globin $(\mathrm{M})$, and human insulin (I) gene probes as indicated. The human $\beta$-globin probe was the Eco Ri-Bam HI IVS- 2 fragment. The mouse $\beta$-major globin probe was the Hind III-Pst I IVS-2 fragment. The human insulin gene probe was a $1.8 \mathrm{~kb}$ Bam $\mathrm{H}$ fragment described by Bell et al., 1982

letter is placed either $5^{\prime}$ or $3^{\prime}$ to the gene (Banerji et al., 1981).

The activation of a variety of glucocorticoid-responsive genes is mediated by the binding of the hormone-receptor complex to the gene. Specific binding of the glucocorticoid receptor to MTV DNA in vitro occurs at sites both within and upstream of the transcribed LTR region (Payvar et al., 1983). This implies that DNA sequences both within and upstream of the gene may regulate its activation. The results described in this paper may similarly indicate that DNA sequences both within and upstream of the globin gene may play a role in their activation during erythroid differentiation. Whether the activation is accomplished by the binding of a positive stimulatory factor(s) or the removal of a negative repressive factor(s) supplied in trans by the MEL cell during differentiation is not clear from these results. The low levels of expression obtained with the $5^{\prime}$ $\beta$-globin constructs, $5^{\prime} \beta-3^{\prime} \mathrm{H} 2$ (Figure 7 ) suggest that the $\beta$-globin promoter might be very weak or repressed in undifferentiated MEL cells. Although these results cannot be quantitated reliably, it is tempting to suggest that a negative regulation would operate on the $5^{\prime}$ end and a positive regulation on the $3^{\prime}$ end of the $\beta$-globin gene. The induction process would only operate after the $\beta$-globin chromatin had been activated during erythroid differentiation in vivo (Groudine et al., 1981; Groudine et al., 1983). In one form of $\gamma \beta$-thalassaemia (van der Ploeg et al., 1980; Kioussis et al., 1983), a large deletion has positioned an unknown locus next to the $\beta$-globin gene resulting in an inactive chromatin structure and a silencing of the gene. When this $\beta$-globin gene is cloned and introduced into MEL cells, it is expressed and induced normally (Wright, unpublished observation). Because this abnormal $\beta$-globin locus can respond normally to MEL cell differentiation, and because the heterozygous patient also contains a normal and expressed $\beta$-globin allele, it suggests that factors that act in trans could only act in vivo after the activation of globin chromatin structure.

\section{Experimental Procedures}

\section{Transformation and induction of MEL Cells}

tk- MEL cells (Spandidos and Paul, 1982) were maintained in $\alpha$-MEM medium supplemented with $10 \% \mathrm{FCS}$. Cells were transformed as described (Wigler et al., 1979) by adding $1 \mu \mathrm{g}$ tk plasmid (pRT1 or $\beta \mathrm{pRT}$ ) plus $20 \mu \mathrm{g}$ nonselectable DNA (rabbit $\beta$-globin mutant or hybrid gene) per $10^{6}$ cells. $\mathrm{tk}^{+}$transformants were selected in $\alpha$-MEM supplemented with $10 \%$ FCS, $15 \mu \mathrm{g} / \mathrm{ml}$ hypoxanthine, $0.5 \mu \mathrm{g} / \mathrm{ml}$ aminopterin, $5 \mu \mathrm{g} / \mathrm{ml}$ thymidine.

MEL transformants were induced into differentiation by culturing for 3 days in the presence of $3 \mathrm{mM} \mathrm{HMBA}$

\section{Purification of RNA from MEL Transformants}

$10^{7}$ cells were lysed with $1-\mathrm{ml} 6 \mathrm{M}$ guanidinium chloride and phenol extracted. Nucleic acid was ethanol precipitated, dissolved in $10 \mathrm{mM}$ Tris (pH 7.5), $10 \mathrm{mM} \mathrm{MgCl}_{2}, 50 \mathrm{mM} \mathrm{NaCl}$, and treated with RNAase-free DNase RNA was finally phenol extracted and ethanol precipitated

\section{S1 Nuclease Analysis}

Levels of globin mRNA in MEL transformants were measured by S1 nuclease analysis (Berk and Sharp, 1977; Weaver and Weissmann, 1979) using end-labeled DNA probes. Probes were end labeled by T4 polynucleotide kinase or reverse transcriptase to a specific activity of $>10^{7} \mathrm{cpm} / \mu \mathrm{g}$. Labeled probe was hybridized to $10-30 \mu \mathrm{g}$ samples of total cellular RNA in $10 \mu l 40 \mathrm{mM}$ PIPES (pH 6.4), $400 \mathrm{mM} \mathrm{NaCl}, 1 \mathrm{mM}$ EDTA, and $80 \%$ recrystallized formamide for $8-12 \mathrm{hr}$. Hybridization temperatures were as indicated in the figure legends. After hybridization, samples were digested for $2 \mathrm{hr}$ with $3000 \cup \mathrm{S} 1$ nuclease in $300 \mu \mathrm{l} 200 \mathrm{mM} \mathrm{NaCl}, 30 \mathrm{mM}$ NaAc $(\mathrm{pH} 4.8), 2 \mathrm{mM} \mathrm{ZnSO}_{4}$; digestion was at $20^{\circ} \mathrm{C}$ unless otherwise stated. In some instances this resulted in an overdigestion of the RNA-DNA hybrids (e. g. Figure 7b). $S 1$ protected DNA was ethanol precipitated and electrophoresed on a $7 \mathrm{M}$ urea $7 \%$ acrylamide gel. The amount of protected probe was quantitated by scanning the autoradiographs.

\section{Transcription in Isolated Nuclei}

Transcription in isolated nuclei from differentiated and nondifferentiated MEL transformants was carried out as described in Groudine et al. (1984) Each transcription reaction contained $5 \times 10^{7}$ nuclei and $300 \mu \mathrm{Ci}{ }^{32} \mathrm{P}$.UTP (3000 Ci/mmole).

Purified DNA fragments were bound to a $0.45 \mu \mathrm{m}$ nitrocellulose filter as described by Kafatos et al. (1979). Two micrograms of fragment was loaded per dot. Individual dots were hybridized to labeled nuclear transcripts in a $400 \mu$ l volume as described in Groudine et al. (1984). Each hybridization contained nuclear RNA from $10^{7}$ cells, which corresponded to 5-10 $\times 10^{7}$ $\mathrm{cpm}$ for the uninduced cells and $2-5 \times 10^{7} \mathrm{cpm}$ for the induced cells. After hybridization, the filters were washed to a stringency of $0.3 \times$ SSC.

\section{Acknowledgments}

We are grateful to Cora O'Carroll for typing this manuscript. A. R. was supported by a fellowship from the "Friends of the Hebrew University." This work was supported by the Medical Research Council.

The costs of publication of this article were defrayed in part by the payment of page charges. This article must therefore be hereby marked "advertisement" in accordance with 18 U.S.C. Section 1734 solely to indicate this fact

Received May 8, 1984; revised June 6, 1984

\section{References}

Banerii, J., Rusconi, S., and Schaffner, W. (1981). Expression of a $\beta$-globin gene is enhanced by remote SV40 DNA sequences. Cell 27, 299-308.

Banerji, J., Olson, L., and Schaffner, W. (1983). A lymphocyte-specific cellular enhancer is located downstream of the joining region in immuno globulin heavy chain genes. Cell 33, 729-740.

Bell, G. I., Karam, J. H., and Rutter, W. J. (1981). Polymorphic DNA region adjacent to the $5^{\prime}$ end of the human insulin gene. Proc. Nat. Acad. Sci. USA 78, 5759-5763.

Berk, A. J., and Sharp, P. A. (1977). Sizing and mapping of early adenovirus 
mRNAs by gel electrophoresis of $\mathrm{S} 1$ endonuclease-digested hybrids. Cell 12, 721-732.

Bogenhagen, D. F., Sakonju, S., and Brown, D. D. (1980). A control region in the center of the 5S RNA gene directs specific initiation of transcription II. The $3^{\prime}$ border of the region. Cell 19, 27-35.

Chao, M. V., Mellon, P., Charnay, P., Maniatis, T., and Axel, R. (1983). The regulated expression of $\beta$-globin genes introduced into mouse erythroleukemia cells. Cell 32, 483-493.

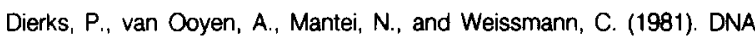
sequences preceding the rabbit $\beta$-globin gene are required for formation in mouse $L$ cells of $\beta$-globin RNA with correct $5^{\prime}$ terminus. Proc. Nat. Acad. Sci. USA 78, 1411-1415.

Friend, C., Scher, W. Holland, J. G., and Sato, T. (1971). Hemoglobin synthesis in murine virus induced leukemic cells in vitro: stimulation of enythroid differentiation by dimethyl sulfoxide. Proc. Nat. Acad. Sci. USA $68,378-382$

Grosveld, F. G., Lund, T., Murray, E. J., Mellor, A. L., Dahl, H. H. M., and Flavell, R. A. (1982). The construction of cosmid libraries which can be used to transform eukaryotic cells. Nuct. Acids Res. 10, 6715-6732.

Grosveld, G. C., deBoer, E., Shewmaker, C. K., and Flavell, R. A. (1982a). DNA sequences necessary for the transcription of the rabbit $\beta$-globin gene in vivo. Nature 295, 120-126.

Grosveld, G. C., Rosenthal, A., and Flavell, R. A. (1982b). Sequence requirements for the transcription of the rabbit $\beta$-globin gene in vivo: the -80 region. Nucl. Acids Res. 10, 4951-4971.

Groudine, M., and Casimir, C. (1984). Post-transcriptional regulation of the chicken thymidine kinase gene. Nucl. Acids Res. 12, 1427-1446.

Groudine, M., Peretz, M., and Weintraub, H. (1981). Transcriptional regulation of hemoglobin switching in chicken embryos. Mol. Cell. Biol. 1, 281288

Hofer, E., Hofer-Warbinek, R., and Darnell, J. E., Jr. (1982). Globin RNA transcription: a possible termination site and demonstration of transcriptional control correlated with altered chromatin structure. Cell 29, 887-893.

Kafalos, F. C., Jones, C. W., and Efstratiadis, A. (1979). Determination of nuleic acid sequence homologies and relative concentrations by a dot hybridization procedure. Nucl. Acids Res. 7, 1541-1551.

Kioussis, D., Vanin, E., deLange, T., Flavell, R., and Grosveld, F. G. (1983) $\beta$-globin gene inactivation by DNA translocation in $\gamma \beta$-thalassaemia. Nature $38,662-666$

Kurts, D. T. (1981). Hormonal inducibility of rat $\alpha_{2 \mu}$ glabulin genes in transfected mouse cells. Nature 291, 629-631.

Marks, P. A., and Rifkind, R. A. (1978), Erythroleukemic differentiation. Ann. Rev. Biochem, 47, 419-426.

Nudel, U., Salmon, J., Fibach, E., Terada, M., Rifkind, R., Marks, P. A., and Bank, A. (1977). Accumulation of $\alpha$ - and $\beta$-globin messenger RNAs in mouse erythroleukemia cells. Cell 12, 463-469.

Orkin, S. H., and Swerdlow, P. S. (1977). Globin RNA synthesis in vitro by isolated erythroleukemia cell nuclei: direct evidence for increased transcrip. tion during erythroid differentiation. Proc. Nat. Acad. Sci. USA 74, 24752479.

Payvar, F., DeFranco, D., Firestone, G. L., Edgar, B., Wrange, O., Okret, S., Gustafsson, J.A., and Yamamoto, K. R. (1983). Sequence-specitic binding of glucocorticoid receptor to MTV DNA at sites within and upstream of the transcribed region. Cell $35,381-392$.

Pelham, H. R. B., and Bienz, M. (1982). A synthetic heat shock promoter element confers heat-inducibility on the herpes simplex virus thymidine kinase gene. EMBO J. 1, 1473

Queen, C., and Baltimore, D. (1983). Immunoglobulin gene transcription is activated by downstream sequence elements. Cell $33,741-748$.

Ragg, H., and Weissmann, C. (1983). Not more than 117 base pairs of $5^{\prime}$ flanking sequence are required for inducible expression of a human IFN- $\alpha$ gene. Nature 303, 439-442.

Reuben, R. C. Wife, R. L., Breslow, R., Rifkind, R. A., and Marks, P. A. (1976). A new group of potent inducers of differentiation in murine erythroleukemia cells. Proc. Nat. Acad. Sci. USA 73, 862-866.

Robins, D. M., Paek, I., Seeburg, P. H., and Axel, R. (1982). Regulated expression of human growth hormone genes in mouse cells. Cell 29, 623631

Ross, J., Itawa, Y., and Leder, P. (1972). Globin messenger RNA induction during erythroid differentiation of cultured leukemia cells. Proc. Nat. Acad. Sci. USA 69, 3620-3623.

Spandidos, D. A., and Paul, J. (1982). Transfer of human globin genes to erythroleukemic mouse cells. EMBO J. 1, 15-20.

van der Ploeg. L. H. T., Konings, A., Oort, M., Roos, D., Bernini, L. F., and Flavell, R. A. (1980). $\gamma \cdot \beta$-thalassaemia: deletion of the $\gamma$-and $\delta$-genes influences $\beta$-globin gene expression in man. Nature 283, 637-642. .

Weaver, R. F., and Weissmann, C. (1979). Mapping of RNA by a modification of the Berk-Sharp procedure: the $5^{\prime}$ termini of $15 S \beta$-globin mRNA precursor and 10S $\beta$-globin mRNA have identical map coordinates. Nucl. Acids Res. 6, 1175-1192

Weidle, U., and Weissmann, C. (1983). The $5^{\prime}$-flanking region of a human IFN- $\alpha$ gene mediates viral induction of transcription. Nature 303, 442-446. Weiss, E. H., Mellor, A., Golden, L., Fahrner, K., Simpson, E., Hurst, J., and Flavell, R. A. (1983). Structure of a mutant $\mathrm{H}-2$ gene: generation of polymorphism in $\mathrm{H}-2$ genes by gene conversion-like events. Nature 301 , 671-674.

Wigler, M., Sweet, R., Sim, G. K., Wold, B., Pellicer, A., Lacy, E., Maniatis, T., Silverstein, S., and Axel, R. (1979). Transformation of mammalian cells with genes from procaryotes and eucaryotes. Cell 16, 777-785.

Wright, S., deBoer, E., Grosveld, F. G., and Flavell, R. A. (1983). Regulated expression of the human $\beta$-globin gene family in murine erythroleukemic cell hybrids. Nature $305,333-336$.

Zinn, K., DiMaio, D., and Maniatis, T. (1983). Identification of two distinct regulatory regions adjacent to the human $\beta$-interferon gene. Cell $34,865-$ 879 